
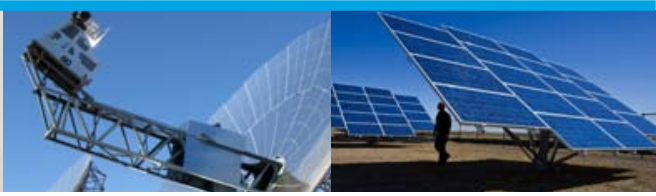

\title{
Life Cycle Greenhouse Gas Emissions from Concentrating Solar Power
}

Over the last thirty years, more than 100 life cycle assessments (LCAs) have been conducted and published for a variety of utility-scale concentrating solar power (CSP) systems. These LCAs have yielded wide-ranging results. Variation could be attributed to differences in technologies evaluated (i.e., differing system designs, commercial versus conceptual systems, system operating assumptions, technology improvements over time), and LCA methods and assumptions. The National Renewable Energy Laboratory (NREL) recently led the Life Cycle Assessment (LCA) Harmonization Project, a study that makes great strides in clarifying inconsistent and conflicting GHG emission estimates in the published literature while providing more precise estimates of GHG emissions from utility-scale CSP systems. Analysts developed and applied a systematic approach to review LCA literature, identify primary sources of variability and, where possible, reduce variability in GHG emissions estimates through a process called "harmonization."

LCA is a standardized technique that tracks all material, energy, and pollutant flows of a system - from raw material extraction, manufacturing, transport, and construction to operation and endof-life disposal. LCA can help determine environmental burdens from "cradle to grave" and facilitate fair comparisons of energy technologies. Comparing life cycle stages and proportions of GHG emissions from each stage for CSP and coal shows that, for coalfired power plants, fuel combustion during operation emits the vast majority of GHGs (see figure below). It also demonstrates that for CSP plants, the majority of GHG emissions are upstream of operation.

Published results from 125 studies of CSP systems were reviewed and screened. Ten studies on parabolic trough and power tower passed the screening (providing 19 and 17 estimates of life cycle GHG emissions, respectively) and were included in this analysis. Results based on the six estimates for parabolic dish technologies are reported in our journal publication (Burkhardt et al. 2012).

\section{Life Cycle Stages}

Concentrating Solar Power
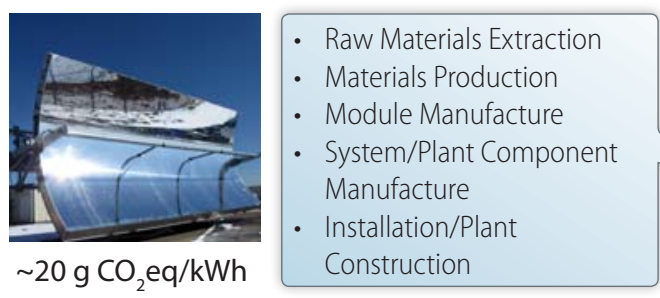

$\sim 60 \%-70 \%$

Coal

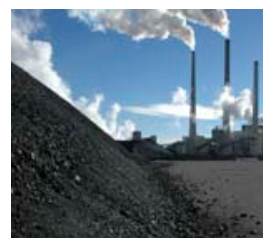

$\sim 1000 \mathrm{~g} \mathrm{CO}_{2}$ eq $/ \mathrm{kWh}$

\section{Upstream Processes}

\section{Operational Processes}

Downstream Processes

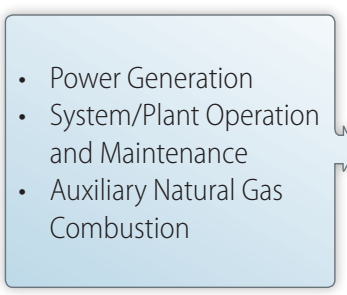

$\sim 21 \%-26 \%$

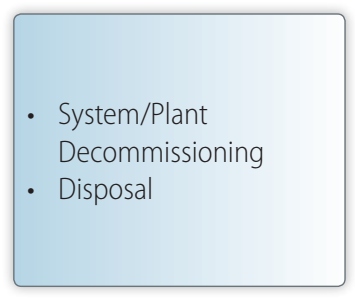

$\sim 5 \%-20 \%$

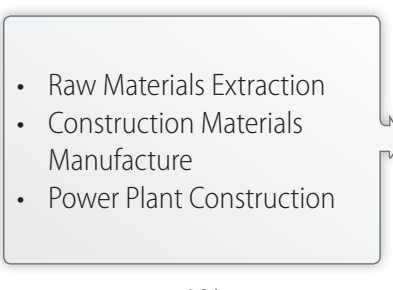

$<1 \%$

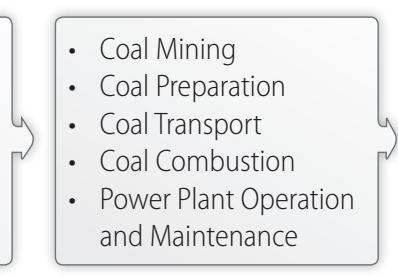

$>98 \%$

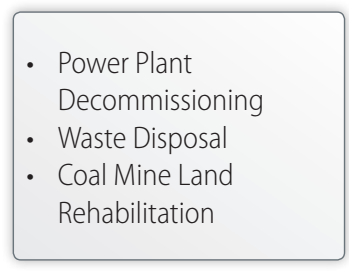

$<1 \%$
Source: Burkhardt et al. (2012) and Whitaker et al. (2012), NREL/PIX 18553 and iStock/1627655, Top (left to right): Photo from iStock/13737597, NREL/PIX 18553, iStock/12123595, NREL/PIX 16933, NREL/PIX 18381, NRE/PIX 19163

\section{LCA of Energy Systems}

LCA can help determine environmental burdens from "cradle to grave" and facilitate fair comparisons of energy technologies. Comparing life cycle stages and proportions of GHG emissions from each stage for CSP and coal shows that, for coal-fired power plants, fuel combustion during operation emits the vast majority of GHGs. It also demonstrates that for CSP plants, the majority of GHG emissions are upstream of operation. 


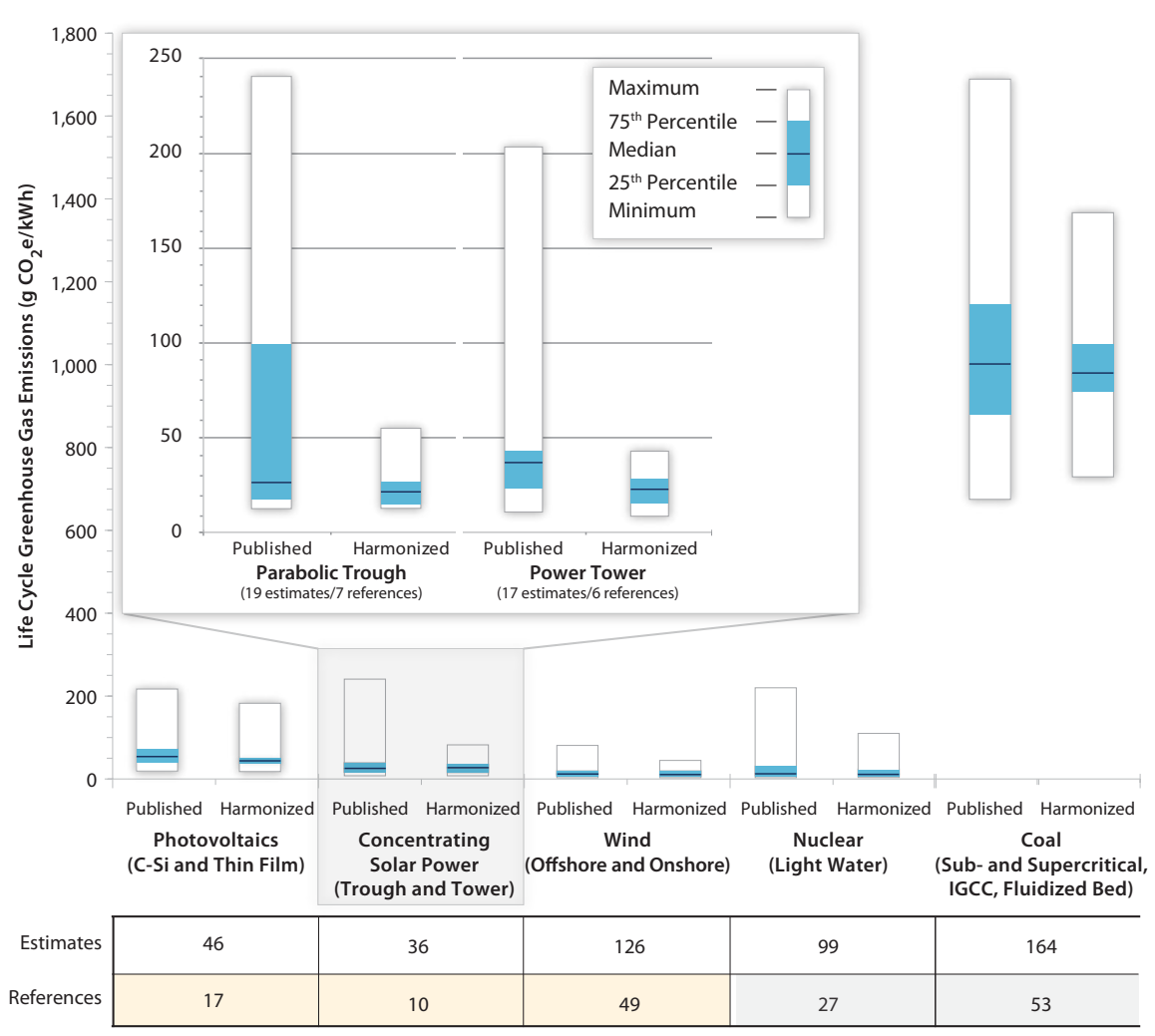

Summary of results of the systematic review and harmonization of estimates of life cycle GHG emissions for selected electricity generation technologies, with a focus on CSP technologies. See www.nrel.gov/harmonization for more information.

Published estimates were adjusted through harmonization to ensure consistency in the following factors:

1. Solar fraction, the proportion of electricity produced only from solar energy, was adjusted to a value of 1 . A facility with solar fraction less than 1 is a hybrid operating plant that combusts natural gas to generate a portion of its electrical output.

2. Direct normal irradiance, the amount of solar energy per unit area incident upon the collector area of the solar field during one year, was adjusted to a value of 2,400 kilowatt hours per square meter per year $\left(\mathrm{kWh} / \mathrm{m}^{2} / \mathrm{yr}\right)$. This is a typical value for the U.S. Southwest and other high quality resource areas.

3. Solar-to-electric efficiency, the percentage of solar energy converted to electricity, was adjusted to $15 \%$ for trough and 20\% for tower systems.

4. Operating lifetime was adjusted to a value of 30 years.

For trough systems only, a second level of harmonization (full harmonization) was results. results show that: coal. reducing variability by over $50 \%$.

- Harmonization lowers the median of CSP systems.
- Tower and trough technologies have similar life cycle GHG emissions, with median life cycle GHG emission estimates of 22 and $23 \mathrm{~g} \mathrm{CO}$ eq/kWh, respectively, after harmonization.

For tower systems, adjusting reported data to a consistent operating lifetime achieved the greatest reduction in variability $(-25 \%)$. The solar fraction had the greatest impact on variability of trough systems, reducing variability by $80 \%$.

By adjusting published estimates to consistent values for key input parameters, the harmonization process increased the precision of life cycle GHG emission estimates in the literature, providing a useful first approximation of life cycle emissions for generic CSP facilities. Additional LCA studies, particularly for tower and dish systems, could help to better understand the key sources of variability in life cycle GHG emissions for CSP systems.

\section{References}

Burkhardt, J.; Heath, G.; Cohen, E. (2012). "Life Cycle Greenhouse Gas Emissions of Trough and Tower Concentrating Solar Power Electricity Generation: Systematic Review and Harmonization." Journal of Industrial Ecology (16:S1); pp. S93-S109.

Whitaker, M.; Heath, G.; O’Donoughue, P.; Vorum, M. (2012.) "Life Cycle Greenhouse Gas Emissions of CoalFired Electricity Generation: Systematic Review and Harmonization." Journal of Industrial Ecology (16:S1); pp. S53-S72.

of global warming intensities of materials and activities $\left(\mathrm{CO}_{2}\right.$ eq per material mass or unit activity) during construction and operation. See Burkhardt et al. (2012) for full harmonization

The life cycle GHG emissions for CSP systems are compared with other electricity generation technologies in the figure on this page. These

- Total life cycle GHG emissions from CSP systems are similar to other renewables and nuclear energy, and much lower than

- Harmonization clarifies estimates of life cycle GHG emissions for CSP systems, estimated life cycle GHG emissions for

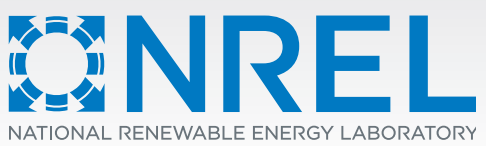

National Renewable Energy Laboratory 15013 Denver West Parkway, Golden, C0 80401

303-275-3000 • www.nrel.gov

NREL is a national laboratory of the U.S. Department of Energy, Office of Energy Efficiency and Renewable Energy, operated by the Alliance for Sustainable Energy, LLC.

NREL/FS-6A20-56416・ November 2012 containing at least 50\% wastepaper, including $10 \%$ post consumer waste. 